\title{
Influence of seed associated mycoflora on germination of maize and rice crops
}

\author{
PRAHLAD KUMAR BAGRI* AND USHA BHALE
}

Department of Plant Pathology, Jawaharlal Nehru Krishi Vishwavidyalya, Krishinagar, JABALPUR (M.P.) INDIA

\section{ARITCLE INFO}

Received : 20.12 .2016

Revised : 26.02 .2017

Accepted : 03.03.2017

\section{KEY WORDS :}

Germination, Maize, Mycoflora, Rice, Standard blotter method

*Corresponding author:

Email : bagri.prahlad@gmail.com

\begin{abstract}
Maize (Zea maydis) and Rice (Oryza sativa L.) are the major grain crops of the India, which is cultivated in different regions of country. During harvest and post-harvest phases several fungi have been reported that include Fusarium spp., Aspergillus spp., Penicillium spp., Rhizopus spp, Mucor spp. and Alternaria spp. in Maize and Rhizopus stolonifer, Aspergillus spp. Fusarium moniliforme, Phoma sp. Bipolaris oryzae, Curvularia lunata, Penicillium sp. Alternaria tenuissima, Nigrospora oryzae, Chaetomium globosum and Tilletia barclyana in rice. With a view to analyze the seed lots for possible use in seed multiplication, present investigation was undertaken, that were serve as a base for improvement and enhancement of quality of seed lots. The study was conducted at department of plant pathology, JNKVV, Jabalpur (Madhya Pradesh). The results obtained from the study revealed that a fair difference in the seed germination was found when the seeds were placed between the blotter as compared to top of the blotter papers as per protocol of ISTA. The discoloured and shriveled seed had lesser germination as compared to apparently normal seeds.
\end{abstract}

How to view point the article : Bagri, Prahlad Kumar and Bhale, Usha (2017). Influence of seed associated mycoflora on germination of maize and rice crops. Internat. J. Plant Protec., 10(1) : $42-$ 46, DOI : 10.15740/HAS/IJPP/10.1/42-46. 